\title{
KEMAMPUAN ELEKTRODEPOSISI UNTUK MENURUNKAN KADAR LOGAM BERAT SENG (Zn) PADA LIMBAH CAIR PT. SERMANI STEEL Ronny ${ }^{1}$ dan Baktiar ${ }^{2}$ \\ ${ }^{1}$ Poltekkes Kemenkes Makassar \\ baktiar@poltekkes-mks.ac.id
}

\begin{abstract}
PT. Sermani Steel is one of the electroplating Industries that perform metal coating. The metal coating process consists of washing, cleaning, coating, rinsing, and drying. Water derived from metal washing, cleaning and rinsing usually contain heavy metals such as $\mathrm{Cu}, \mathrm{Zn}, \mathrm{Cr}, \mathrm{Cd}, \mathrm{Ni}$, and $\mathrm{Pb}$. The presence of heavy metals in waters, especially heavy metals zinc ( $\mathrm{Zn})$ that exceeds the limit can cause health problems and environmental pollution. The purpose of this research is to know the capability of electrodeposition in reducing the heavy metal content of zinc $(\mathrm{Zn})$ in the waste water of PT. Sermani Steel then the results of laboratory tests are presented in the form of tables and graphs and analyzed descriptively. The results showed that there was an average decrease in the level of heavy metal zinc ( $\mathrm{Zn}$ ) after the treatment of 60 minutes contact time, namely $1.91 \mathrm{mg} / \mathrm{L} \mathrm{(88.58 \% )}$ and 90 minutes contact time, $2.03 \mathrm{mg} / \mathrm{L}$ (93.98\%) and at 120 minutes contact time, $2.12 \mathrm{mg} / \mathrm{L}(98.30 \%)$. According to the statistics Kruskal Wallis Testtest, it was obtained $p=0.027$ where $p<\alpha$, it was stated that there was a significant difference in the reduction of heavy metal zinc ( $\mathrm{Zn}$ ) with a contact time of 60 minutes, 90 minutes and 120 minutes. It was concluded that the electrodeposition of 12 Volt voltage using stainless steel electrodes was able to reduce levels of heavy metals zinc (Zn) in waste water PT. Sermani Steel and has fulfilled Regulation of the Minister of Environment No. 5 of 2014 which is $1.0 \mathrm{mg} / \mathrm{L}$.
\end{abstract}

Keywords: Wastewater, heavy metal Zinc (Zn), electrodeposition, contact time

\section{ABSTRAK}

PT. Sermani Steel merupakan salah satu Industri elektroplating yang melakukan pelapisan logam. Proses pelapisan logam terdiri atas pencucian, pembersihan, pelapisan, pembilasan dan pengeringan. Air yang berasal dari proses pencucian logam, pembersihan dan pembilasan biasanya mengandung logam-logam berat seperti $\mathrm{Cu}, \mathrm{Zn}, \mathrm{Cr}$, $\mathrm{Cd}, \mathrm{Ni}$ dan $\mathrm{Pb}$. Adanya logam berat di perairan khususnya logam berat seng $(\mathrm{Zn})$ yang melampaui batas dapat menyebabkan gangguan kesehatan dan pencemaran lingkungan. Tujuan penelitian ini mengetahui kemampuan elektrodeposisi dalam menurunkan kadar logam berat seng ( $\mathrm{Zn}$ ) pada limbah cair PT. sermani steel kemudian hasil pemeriksaan laboratorium disajikan dalam bentuk tabel dan grafik serta dianalisa secara deskriftif. Hasil penelitian menunjukkan bahwa terjadi rata - rata penurunan terhadap kadar logam berat Seng ( $\mathrm{Zn})$ setelah perlakuan waktu kontak 60 menit yaitu, $1,91 \mathrm{mg} / \mathrm{L}(88,58 \%)$ dan waktu kontak 90 menit yaitu, 2,03 mg/L (93,98\%) dan pada waktu kontak 120 menit yaitu, 2,12 mg/L (98,30\%). Sesuai uji statistik Kruskal Wallis Test diperoleh nilai $p=0,027$ dimana $p<\alpha$, maka dinyatakan ada perbedaan yang signifikan terhadap penurunan kadar logam berat Seng (Zn) dengan waktu kontak 60 menit, 90 menit, dan 120 menit. Disimpulkan bahwa elektrodeposisi tegangan 12 Volt menggunakan elektroda stainless steel mampu menurunkan kadar logam berat Seng (Zn) pada limbah cair PT. Sermani Steel dan telah memenuhi Peraturan Menteri Lingkungan Hidup No. 5 Tahun 2014 yaitu 1,0 mg/L.

Kata Kunci : Limbah cair, logam berat Seng (Zn), elektrodeposisi , waktu kontak.

\section{PENDAHULUAN}

Kegiatan pembangunan yang dilakukan oleh beberapa negara yang sedang berkembang tantangan yang dihadapi adalah meningkatnya jumlah penduduk setiap tahunnya serta isu kualitas lingkungan yang menjadi permasalahan. Pemerintah indonesia telah menerapkan konsep SDGs (Sustainable Development Goals) dalam rencana pembangunan nasional (RPJMN 20152019) dengan salah satu kebijakan terkait dengan sumber daya alam dan lingkungan hidup adalah ekonomi hijau, yaitu meningkatkan pengelolaan dan pemanfaatan sumber daya alam berkelanjutan dengan menyeimbangkan antara pemanfaatan dan kelestarian. Aspek lingkungan hidup telah menjadi salah satu titik berat dalam konsep pembangunan berkelanjutan di Indonesia, dan untuk mencapai tujuan pembangunan tersebut perlu dilakukan pemantauan dan pengelolaan lingkungan hidup. (BPS, 2016)
Seiring berkembangnya teknologi, industri kian hari berkembang pesat. Industri-industri tersebut selain memberikan dampak positif berupa perluasan lapangan pekerjaan dan peningkatan pendapatan penduduk, juga memiliki dampak negatif yaitu tingginya laju perubahan penggunaan lahan yang tidak sesuai dengan kaidah ekologi, urbanisasi yang kurang terkendali, pertumbuhan penduduk yang tinggi, serta pencemaran perairan akibat pembuangan air limbah. (Heru, 2014)

Industri seng PT. Sermani Steel merupakan salah satu Industri elektroplating yang melakukan pelapisan logam. Proses pelapisan logam dilakukan untuk menghindari korosi pada seng dan disesuaikan dengan kebutuhan serta kegunaan masing-masing material.

Proses pelapisan logam terdiri atas pencucian, pembersihan, pelapisan, pembilasan dan pengeringan. Air yang berasal dari proses pencucian logam, pembersihan dan pembilasan 
biasanya mengandung logam-logam berat seperti $\mathrm{Cu}, \mathrm{Zn}, \mathrm{Cr}, \mathrm{Cd}$, Ni dan Pb. (Rachmanita, 2012)

Adanya logam berat di perairan khususnya logam berat seng $(\mathrm{Zn})$ yang melampaui batas dapat menyebabkan gangguan kesehatan dan pencemaran lingkungan yang dapat menimbulkan rasa kesat pada air dan dapat menimbulkan gejala muntaber pada manusia, walaupun seng merupakan logam yang dibutuhkan oleh tubuh namun berbahaya jika melebihi ambang batas maka diperlukaan pengolahan terlebih dahulu sebelum dibuang ke lingkungan. (Irdawati, 2012)

Menurut Tri Widayanto, (2016) Pengolahan limbah yang relatif mampu menurunkan kadar logam berat pada limbah cair yaitu metode pengambilan kembali (recovery) dengan cara elektrodeposisi. Proses pengolahan yang disebut juga dengan elektrodeposisi, yaitu suatu proses pengendapan/deposisi

pelindung di atas logam lain dengan cara elektrolisa.

\section{Bahan dan Metode}

\section{Lokasi Penelitian}

a. Pengambilan sampel penelitian dilaksanakan di industri PT. Sermani Steel, Kota Makassar, Sulawesi Selatan.

b. Pelaksanaan Penelitian dilaksanakan di Laboratorium Terapan Jurusan Kesehatan Lingkungan Poltekkes Kemenkes Makassar.

c. Pemeriksaan Sampel dilakukan di Balai Besar Industri Hasil Perkebunan (BBIHP), JIn. Prof. Dr. Basalamah No. 28, Karampuang, Kota Makassar

\section{Desain dan Variabel Penelitian}

Jenis penelitian yang digunakan adalah Kuantiatif dengan metode Experiment untuk membandingkan sebelum perlakuan dan setelah perlakuan (Pretest-Posttest) menggunakan Elektrodeposisi untuk menurunkan kadar logam berat seng $(Z n)$ pada Imbah cair PT. Sermani Steel.

Variabel yang berpengaruh terhadap variabel terikat (Dependen) dalam penelitian ini yaitu proses Elektrodepsisi tegangan 12 Volt menggunakan elektroda stainless steel dengan waktu kontak selama 60 menit, 90 menit, dan 120 menit.

\section{Sampel}

Sampel dalam penelitian ini adalah sebagian air limbah yang belum mendapatkan perlakuan (treatment) dengan metode pengambilan sampel menggunakan Grab sample (teknik pengambilan sampel secara acak tanpa seleksi khusus) yang di ambil langsung dari limbah cair PT. Sermani Steel. Untuk tiga perlakuan total sampel limbah cair dibutuhkan sebanyak 24 Liter dengan masing - masing tiga replikasi dan satu kontrol.

\section{Pengumpulan Data}

a. Data Primer

Data primer adalah data yang diperoleh berdasarkan hasil pemeriksaan laboratorium kadar logam berat seng (Zn).

b. Data Sekunder

Data sekunder adalah data yang diperoleh dari berbagai referensi baik artikel-artikel, jurnal, buku maupun literatur yang ada dengan penelitian ini.

\section{Analisa Data}

Data yang telah diperoleh dari hasil pemeriksaan laboratorium dan dianalisa secara deskriktif komparatif digunakan untuk mencari persentasi penurunan kadar logam berat seng (Zn). Analisis menggunakan Statistik Kruskal Wallis Test untuk mengetahui ada atau tidaknya perbedaan kadar logam berat seng $(\mathrm{Zn})$ sebelum dan sesudah perlakuan menggunakan elektrodeposisi. Hasil dimasukkan dalam tabel dan diuraikan dalam bentuk narasi selanjutnya dibuat suatu kesimpulan.

\section{Hasil Penelitian}

Berdasarkan hasil analisa dan kualitas air limbah PT. Sermani Steel yang diteliti melalui tahap pemeriksaan awal sebelum dan setelah pengolahan diketahui bahwa kadar logam berat Seng $(Z n)$ pada air limbah yaitu, 2,16 mg/L dan untuk kadar logam berat Seng $(\mathrm{Zn})$ setelah dilakukan pengujian pada setiap waktu kontak yaitu, waktu kontak 60 menit sebersar $0,25 \mathrm{mg} / \mathrm{L}$ dengan persentase penurunan $88,58 \%$, waktu kontak 90 menit sebersar $0,13 \mathrm{mg} / \mathrm{L}$ dengan persentase penurunan $93,98 \%$ dan untuk waktu kontak 120 menit sebesar $0,04 \mathrm{mg} / \mathrm{L}$ dengan pesentase penurunan $98,30 \%$. Berikut grafik rata - rata penurunan kadar logam berat Seng ( $\mathrm{Zn}$ ) pada air limbah setelah pengujian menggunakan elektrodeposisi tegangan 12 Volt dengan waktu kontak 60 menit, 90 menit, dan 120 menit.

Tabel. 1

Rata-Rata Penurunan Kadar Logam Berat Seng (Zn) Pada Limbah Cair Menggunakan Elektrodeposisi Tegangan 12 Volt Dengan Waktu Kontak 60 Menit, 90 Menit, dan 120 Menit No Waktu Kadar Seng (Zn) Penurunan 
Jurnal Sulolipu : Media Komunikasi Sivitas Akademika dan Masyarakat

Vol. 18 No 22018

e-issn : 2622-6960, p-issn : 0854-624X

\begin{tabular}{cccccc}
\hline \hline Kontak & $\begin{array}{c}\text { Sebelum } \\
(\mathbf{m g} / \mathbf{L})\end{array}$ & $\begin{array}{c}\text { Sesudah } \\
(\mathbf{m g} / \mathbf{L})\end{array}$ & $\begin{array}{c}\text { Kadar } \\
(\mathbf{m g} / \mathbf{L})\end{array}$ & $\begin{array}{c}\text { Persentase } \\
(\%)\end{array}$ \\
\hline 1 & $\begin{array}{c}60 \\
\text { Menit }\end{array}$ & 2,16 & 0,25 & 1,91 & 88,58 \\
2 & $\begin{array}{c}90 \\
\text { Menit }\end{array}$ & 2,16 & 0,13 & 2,03 & 93,98 \\
3 & $\begin{array}{c}120 \\
\text { Menit }\end{array}$ & 2,16 & 0,04 & 2,12 & 98,30 \\
\hline & Rata-Rata & $\mathbf{2 , 1 6}$ & $\mathbf{0 , 1 4}$ & $\mathbf{2 , 0 2}$ & $\mathbf{9 3 , 6 2}$ \\
\hline
\end{tabular}

Sumber : Data primer 2018

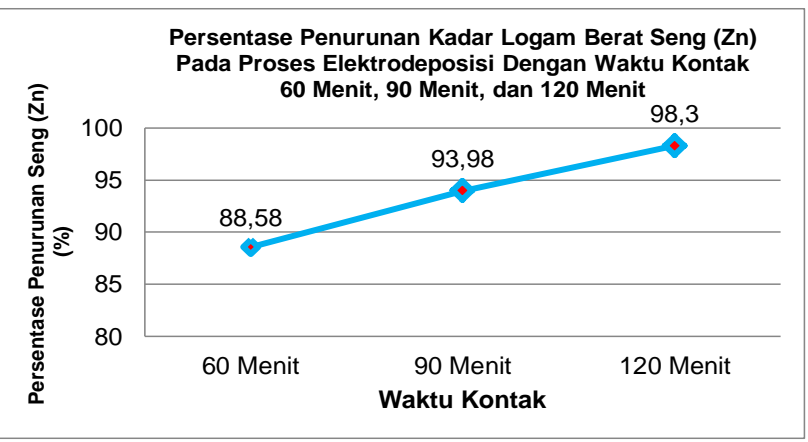

Gambar.1. Grafik Persentase Penurunan kadar Logam Berat Seng (Zn) Dengan Waktu Kontak 60 Menit, 90 Menit, dan 120 Menit

\section{Pembahasan}

1. Penurunan Kadar Logam Berat Seng (Zn) Pada Limbah Cair PT. Sermani Steel Menggunakan Elektrodeposisi Tegangan 12 Volt

Berdasarkan hasil yang dipaparkan diatas dengan menggunakan elektrodeposisi arus 12 volt menggunakan elektroda stainless untuk menurunkan kadar logam berat Seng (Zn) pada limbah cair PT. Sermani Steel dapat dikatakan mampu menurunkan kandungan logam berat seng $(\mathrm{Zn})$ pada limbah cair tersebut. Hasil rata-rata pemeriksaan penurunan kadar logam berat Seng $(\mathrm{Zn})$ menunjukkan adanya pemenuhan hasil yang sesuai dengan baku mutu yang digunakan, namun dalam menjabarkan kondisi dan hal yang mempengaruhi proses pengujian khususnya penurunan kadar logam berat $(Z n)$ sebelum dan setelah pengolahan peneliti menjabarkan secara deskriptif dan pendekatan berdasarkan hasil pengamatan selama penelitian, pengalaman serta teori yang mendukung dari metode yang digunakan. Sebagaimana tujuan dari penelitian ini untuk mengetahui Kemampuan elektrodeposisi dalam menurunkan kadar logam berat seng (Zn) pada limbah cair PT. sermani steel

menggunakan tegangan 12 Volt dengan waktu kontak yang berbeda sebelum dan setelah pengolahan, berdasarkan pengujian yang dilakukan didapatkan penurunan kadar logam berat Seng (Zn) pada setiap waktu kontak yaitu, 60 menit kadar awal yaitu 2,16 mg/L hingga total rata - rata penurunan dari tiga replikasi yaitu $1,91 \mathrm{mg} / \mathrm{L}$ dengan presentase penurunan sebesar $88,58 \%, 90$ menit kadar awal yaitu 2,16 $\mathrm{mg} / \mathrm{L}$ hingga total rata - rata penurunan dari tiga replikasi yaitu 2,03 $\mathrm{mg} / \mathrm{L}$ dengan presentase penurunan sebesar 93,98\%, 120 menit kadar awal yaitu 2,16 $\mathrm{mg} / \mathrm{L}$ hingga total rata - rata penurunan dari tiga replikasi yaitu $2,12 \mathrm{mg} / \mathrm{L}$ dengan presentase penurunan sebesar $98,30 \%$.

Dengan konsep reaksi redoks (reduksi dan oksidasi) menggunakan elektroda stainless steel yang dialiri tegangan 12 Volt mampu menurunkan kadar Seng (Zn) pada limbah cair hingga memenuhi Peraturan Menteri Lingkungan Hidup No.5 Tahun 2014, Tentang Usaha Dan/Atau Kegiatan Pelapisan logam dan Galvanis bahwa kadar Seng (Zn) yang diperbolehkan pada limbah cair yaitu $1,0 \mathrm{mg} / \mathrm{L}$. Peristiwa penguraian zat pada air limbah oleh arus listrik searah (DC) bersumber dari Aki yang dihubungkan pada elektroda yang terbuat dari bahan stainless steel dengan kutub positif (+) atau biasa disebut Anoda dan kutub negatif (-) atau biasa disebut Katoda. Jika arus listrik dialirkan ke dalam air limbah maka unsur yang bermuatan positif (kation) akan mengelami reduksi (penangkapan). Oleh karena itu unsur bermuatan positif akan mengalami pengendapan (reduksi) pada elektroda yang bermuatan negatif (katoda). Reduksi adalah suatu reaksi yang menyebabkan bilangan oksidasi suatu senyawa berkurang karena perpindahan elektron. Pada reduksi ini terjadi proses penangkapan elektron, yaitu menerima elektron dari atom lain. Karena adanya usaha penangkapan elektron disatu sisi, maka ada usaha pelapasan elektron disisi lain yang biasa dikenal dengan reaksi oksidasi. Redoks dapat terjadi akibat adanya tegangan 12 volt yang dialirkan ke unsur logam stainless steel sebagai elektroda ke sampel air limbah yang mengandung logam berat $\left(\mathrm{Zn}^{2+}\right)$ yang bermuatan positif menuju elektroda katoda yang bermuatan negatif sehingga ion logam $\mathrm{Zn}^{2+}$ akan tereduksi menjadi logam $\mathrm{Zn}$ dan mengendap dikatoda sehingga membentuk lapisan logam (deposit). 

logam yang dijadikan sampel mengalami perubahan warna sampel dari keruh menjadi hijau keruh serta menimbulkan gumpalan berwana kecoklatan pada bagian elektroda yang bermuatan negatif (katoda) dan endapan pada dasar wadah simulasi elektrodaposisi.

Proses elektrodeposisi tegangan 12 Volt dengan waktu kontak yang bervariasi dapat mempengaruhi penurunan kadar logam berat pada air limbah khususnya kadar logam berat Seng (Zn). Dengan menggunakan arus listrik searah (DC) 12 Volt yang bersumber dari Aki kemudian terhubungkan dengan kutub positif disebut Anoda sedangkan yang terhubung dengan kutub negatif disebut Katoda. Ketika sumber tegangan digunakan pada sampel air limbah maka kutub positif akan mengeluarkan ion yang bergerak dalam larutan menuju katoda dan disebut sebagai kation dan kutub negatif juga mengeluarkan ion yang bergerak menuju anoda yang disebut anion. Voltase yang digunakan sangat berpengaruh terhadap pendesposisian logam berat. Sesuai yang dikemukakan Azhar, (2014) Pada proses lapis listrik tegangan yag digunakan harus konstan sehingga yang divariasikan hanyalah arusnya saja. Maksudnya, bila luas permukaan benda kerja bervariasi, maka rapat aruslah yang divariasikan sesuai dengan kententuan, sedangkan tegangan tetap. Biasanya tegangan yang digunakan pada operasi lapis listrik adalah $6-12$ Volt. Penelitian yang dilakukan oleh Mukhtar, (2017) dengan menggunakan elektrodeposisi pada pengujian air limbah radiologi rumah sakit terhadap parameter logam berat timbal $(\mathrm{Pb})$ dengan menggunakan variasi arus listrik yaitu 6 Volt, 9 Volt, dan 12 Volt. Hasil penelitian Logam berat Timbal (Pb) sebelum perlakuan (Awal) sebesar $3.16 \mathrm{mg} / \mathrm{l}$ setelah elektrodeposisi pada tegangan 12 Volt penurunan hingga $0,32 \mathrm{mg} / \mathrm{l}$ presentase penurunan $90 \%$. Hal tersebut sejalan dengan penelitian ini karena dinyatakan dengan menggunakan tegangan 12 Volt dapat menurunkan parameter logam berat Seng $(\mathrm{Zn})$ logam berat Seng (Zn) pada limbah cair PT. Sermani Steel dengan waktu kontak yang berbeda antara 60 menit, 90 menit, 120 menit dengan menggunakan tegangan 12 volt mengalami peningkatan yaitu dari, $88,58 \%$ pada waktu kontak 60 menit menjadi $93,98 \%$ pada waktu kontak 90 menit, dan pada waktu kontak 120 menit juga mengalami peningkatan yaitu, $98,30 \%$.

Peningkatan persentase penurunan kadar logam berat Seng (Zn) menggunakan elektrodeposisi tegangan 12 volt dengan waktu kontak yang berbeda menunjukkan adanya perbedaan dari setiap perlakuan. Hal ini sesuai dengan uji statistik Kruskal Wallis Test menggunakan aplikasi SPSS versi 24.00 dan nilai alpha yang digunakan yaitu $\alpha=0,05$ maka diperoleh hasil yaitu nilai $p=0,027$. Berdasarkan hal tersebut dimana $p<\alpha$, maka dapat dinyatakan bahwa $\mathrm{HO}$ ditolak. Hal ini berarti ada perbedaan yang signifikan sebelum perlakuan dan setelah perlakuan pada penurunan kadar logam berat Seng (Zn) terhadap waktu kontak 60 menit, 90 menit, dan 120 menit artinya, semakin lama waktu kontak maka persentase penurunan akan semakin meningkat. Dari ketiga waktu kontak yang digunakan maka yang paling optimum menurunkan kadar logam berat Seng (Zn) pada limbah cari PT. Sermani Steel dengan menggunakan elektrodeposisi tegangan 12 volt adalah waktu kontak 120 menit yaitu sebesar $98,30 \%$ tetapi yang efektif digunakan yaitu waktu kontak 60 menit dengan persentase penurunan $88,58 \%$ dan telah memenuhi Peraturan Menteri Lingkungan Hidup No. 5 Tahun 2014 tentang Baku Mutu Air limbah untuk Usaha Dan/Atau Kegiatan Pelapisan logam dan Galvanis bahwa kadar Seng (Zn) yang diperbolehkan pada limbah cair yaitu 1,0 $\mathrm{mg} / \mathrm{L}$

Penelitian ini dapat diaplikasikan sebagai salah satu alternatif dalam pengolahan air limbah indsutri untuk mengurangi permasalahan kesehatan lingkungan khusunya 
pada pencemaran lingkungan akibat air buangan industri yang dapat berdampak terhadap kesehatan manusia maupun terhadap lingkungan. Upaya penerapan dari sebuah teknologi harus dapat menjawab persoalan dan permasalahan yang dihadapi didasarkan pada ketentuan dan sistem regulasi yang mengatur tetap terjaganya kualitas lingkungan khususnya analisa dan standar baku mutu lingkungan yang terkait pengawasan kualitas air limbah yang dihasilkan usaha maupun industri.

Elektrodepsosisi tegangan 12 Volt terhadap penurunan kadar logam berat Seng (Zn) merupakan sebuah proses pencapaian untuk memberikan salah satu solusi pada sebuah industri yang menghasilkan air buangan dengan memanfaat teknologi untuk pengolahan limbahnya sebelum dibuang kelingkungan agar tidak menimbulkan masalah pencemaran lingkungan dan kesehatan manusia di masa yang akan datang. Aktivitas industri yang semakin berkembang tidak terlepas dari air buangan yang berasal dari kegiatan proses produksi, pada proses produksi PT. Sermani Steel pada tahapan galvanizing line atau pelapisan baja tidak terlepas dari proses kimia yaitu pelapisan zing ingot yang berfungsi untuk melapisi lembaran lembaran baja serta mencegah timbulnya karat dan ammonium clorida yang berfungsi untuk menambah kilap permukaan lembaran seng yang dihasilkan. Seperti yang dikemukakan Racmanita, (2012) Air yang berasal dari proses pencucian logam, pembersihan dan pembilasan biasanya mengandung logamlogam berat seperti $\mathrm{Cu}, \mathrm{Zn}, \mathrm{Cr}, \mathrm{Cd}$, Ni dan $\mathrm{Pb}$

\section{Kelebihan Dan Kekurangan Elektrodeposisi}

Berdasarkan penelitian yang telah dilakukan kelebihan dari elektrodeposisi, diantaranya:
a. Peralatan yang sederhana dan pengoperasian yang sangat mudah,
b. Mampu menurunkan kadar Seng (Zn) sampai memenuhi baku mutu
c. Pemakaian listrik yang tidak terlalu mahal,

Selain itu, elektrodeposisi juga memiliki kekurangan yaitu:

a. Apabila lapisan logam pada elektroda sudah banyak menempel maka perlu dilakukan pengantian elektroda setiap saat.
b. Adanya endapan yang terbentuk sehingga perlu dilakukan penanganan terlebih dahulu sebelum dibuang ke lingkungan

\section{Kesimpulan dan Saran}

1. Kesimpulan

Berdasarkan penelitian ini, elektrodeposisi mampu menurunkan kadar logam berat seng $(\mathrm{Zn})$ pada limbah cair PT. Sermani Steel dengan waktu kontak 60 menit, 90 menit, dan 120 menit sampai memenuhi syarat KemenLH No. 5 Tahun 2014 sehingga disimpulkan sebagai berikut :

a. Waktu kontak 60 menit dinyatakan mampu menurunkan kadar logam berat seng $(\mathrm{Zn})$ dengan rata-rata penurunan yaitu, $1,91 \mathrm{mg} / \mathrm{L}(88,58 \%)$

b. Waktu kontak 90 menit dinyatakan mampu menurunkan kadar logam berat seng $(\mathrm{Zn})$ dengan rata-rata penurunan yaitu, $2,03 \mathrm{mg} / \mathrm{L}(93,98 \%)$

c. Waktu kontak 120 menit dinyatakan mampu menurunkan kadar logam berat seng $(Z n)$ dengan rata-rata penurunan yaitu, $2,12 \mathrm{mg} / \mathrm{L}(98,30 \%)$

\section{Saran}

a. Bagi industiri, Elektrodeposisi tegangan 12 volt menggunakan elektroda stainless steel merupakan salah satu pilihan yang dapat digunakan sebagai salah satu upaya untuk menjaga keseimbangan lingkungan yang lebih baik. Untuk pengaplikasian pada jumlah yang lebih besar dapat dilakukan dengan menambah dan memperluas elektroda. 
Jurnal Sulolipu : Media Komunikasi Sivitas Akademika dan Masyarakat

Vol. 18 No 22018

e-issn : 2622-6960, p-issn : 0854-624X

\section{DAFTAR PUSTAKA}

Azhar A. Saleh. 2014. Elektroplanting Teknik Pelapisan Logam dengan Cara Listrik. Bandung: Penerbit Yrama Widya.

BPS. 2016. Potret Awal Tujuan Pembangunan Berkelanjutan (Sustainable Development Goals) Di Indonesia. Jakarta: Badan Pusat Statistik.

Heru Setiawan. 2014. Pencemaran Logam Berat Di Perairan Pesisir Kota Makassar Dan Upaya Penanggulangannya. Info Teknis EBONI. 11 (1) : $1-13$. (online) https://id.scribd.com/document/361265931/ Pencemaran-Logam-Berat. Diakses 20 Desember 2017.

Irdawati Sunti, Anwar Daud, Syamsuar Manyullei. 2012. Studi Kandungan Logam Berat Seng (Zn) Dalam Air dan Kerang Baja (Anodonta Woodiana) Di Sungai Pangkajene Kabupaten Pangkep. Makassar: Universitas Hasanuddin.

Mukhtar. 2017. Aplikasi Metode Elektrodeposisi Dalam Menurunkan Kandungan Logam Berat Pada Limbah Cair Radiologi Rumah Sakit. Makassar: Jurusan Kesehatan Lingkungan Poltekkes Kementerian Kesehatan Makassar. (Skripsi tidak dipublikasikan).

Rachmanita Nofitasari, Ganjar Samudro, Junaidi. 2012. Studi Penurunan Konsentrasi Nikel Dan Tembaga Pada Limbah Cair Elektroplating Dengan Metode Elektrokoagulasi. Diponegoro: Jurusan Tenik Lingkungan Fakultas Teknik Universitas Diponegoro.

Republik Indonesia. 2014. Permen LH No. 5 Tahun 2014 Tentang Baku Mutu Air Limbah.

Tri Widayanto, dkk. 2016. Recovery Logam Perak Dari Limbah Cair Bekas Pencucian Foto Rontgen: Karakterisasi Elektrokimia. Simposium Nasional RAPI XV. Fakultas Teknik Universitas Muhammadiyah Surakarta. Surakarta. (online). https://publikasiilmiah.ums.ac.id. Diakses 15 Januari 2018. 